\title{
Perspectives
}

\section{A Conversation with Sandra Kouritzin on "Bringing Life to Research: Life History Research and ESL"}

Guofang Li

Sandra Kouritzin's (2000) insightful article on life history research is a mustread for life history researchers and qualitative researchers in general (Vol. 17, No. 2). In her article Kouritzin asserts that life history research, emerging as a powerful research methodology, has enriched and challenged previous theory and research in the positivist paradigm, provided opportunities for the participants to be listened to and to reflect on their adverse experiences, and allowed researchers to be critically involved with their participants. She also suggests that life history research has potential pitfalls such as in representivity, reliability, and verifiability, as well as translation and authorship. As a qualitative researcher, specifically an educational ethnographer, I agree with Kouritzin's positions on the benefits and pitfalls of life history research. However, I would like to take the discussion further to consider other epistemological underpinnings that are not given adequate attention in this article. First, I endeavor to demonstrate that the subjectivity of the researcher is an essential element that needs to be addressed in life history research in ESL, because it is of great significance to the understanding of power relationships between the researcher and the researched, the (re)interpretation and representation of reality or truth of ESL life history. As a researcher of immigrant background, I also think it would be helpful if we consider some implications of ESL life history for participants at an individual level. I argue that recognizing one's subjectivity in ESL life history research will not only benefit the researcher, but also, more important, empower the researched to take actions to improve their conditions.

\section{Subjectivity and ESL Life History Research}

ESL research has mainly been the practice of mainstream researchers' investigation of the nonmainstream researched. With growing awareness of power balance between the researcher and the researched, the researcher's "posturing" of herself or himself becomes a significant factor that he or she must keep in mind throughout the research process (Wolcott, 1992). The epistemology of qualitative research (the relationship between the knower and the reality) is subjective. Subjectivity, which operates throughout the research process, is "an amalgam of the persuasions that stem from the 
circumstances of one's class, statuses, and values interacting with the particulars of one's object of investigation" (Peshkin, 1988, p. 17). Life history research as a form of narrative inquiry is a process of joint meaning construction that involves subjectivity from both the researcher and the researched. Therefore, researchers must be aware of their own biographical bias and subjectivity in order to clarify their theoretical and sociocultural frameworks of reference in the research process.

Researchers' biographical bias and subjectivity originate not only from their professional, but also their personal backgrounds (LeCompte, 1987). Although Kouritzin has addressed some professional influences such as those of the disciplinary tradition of life history, she has not included personal influence in the interpretation and representation of the life history of participants from different backgrounds. In other words, she has not touched on the influence of the researcher's positionality in life history, an important concept that includes the amalgamation of ideological and normative assumptions related to sex, race, class, age, religion, and cultural values. To identify these ideological and normative assumptions is of paramount significance in ESL life history research, especially when the researcher and the researched are from different cultural backgrounds and from different advantaged and disadvantaged social groups. Failing to do so may further marginalize or victimize disadvantaged people (Banks, 1993; Code 1991).

My position is that personal biography, especially the differences in ideological and normative values of the researcher (and the researched), needs to be brought to the center of attention in ESL life history, because subjectivity permeates the entire research process and influences how the researcher constructs, analyzes, interprets, and presents the life history of ESL participants who are frequently from nonmainstream cultural and disadvantaged positions.

I believe that subjectivity plays an important role in shaping the power relationship between the researcher and the researched from the outset of the project. Kouritzin postulates that an equitable power relationships between the researcher and the researched need to be characterized by trust and responsibility, with the researcher's candor and, if possible, empathy. I agree that trust and responsibility are essential to successful life history research. However, Kouritzin's position disguises the unequal power relationship between the researcher and the researched and makes the research process appear to be neutral. The positionality of the researcher in the research process seems to be "objective and value-free." However, researchers enter with our own agendas, objectives, and predispositions. Researchers from academia are often in a more advantaged position because we "maintain power, voice, and authority" (Tierney, 1998, p. 56). With our own research objectives in mind, we "define" in a certain sense what we wish to know or hear from our participants, because the researcher is the authority who is studying the "othered" interviewees (Fine, 1994). So it is crucial for re- 
searchers to become aware of their "subjective researcher $I$ " from the outset of the project. The caveats of Measor and Sikes (1992) derived from their experiences in life history (cited by Kouritzin) are good examples of how researchers often enter the field with professional and personal subjectivity that navigates the research process. Another example is Cary's (1999) article about her master's thesis research using life history. Entering the field with her own values, agendas, and expectations, Cary heard unexpected stories. She writes,

What was my agenda? I was doing my master's research and had not fully considered the possibilities of hearing anything other than "normal" stories (normalized stories?). I expected to hear about a lifelong love of history, travel, fascination with the world, significant incidents as students, terrific or terrible social studies teachers who planted the seeds for future careers by their actions. And I did hear a lot and more, but I did not expect to hear a story of abuse and resistance. (p. 413)

Cary's account of unexpected stories not only raises the important issuewhere the subjective $I$ fits into the research-but also the question of the researcher's representation and interpretation of truth and reality in life history. I agree with Kouritzin's postmodern perspective that truth and reality in life history are multiple and ever-shifting; however, I wish to ask: Because the researcher, in a power position, may enter the field with his or her ideological baggage, whose truth is the truth in the multiple, ever-shifting reality? Without questioning or identifying their subjectivity, researchers may run the risk of representing what they wish to represent from their own perspectives rather than from the those of the participants. Denying the existence of predispositions and assumptions will result in distortion of narrative truth and reality - and further stereotyping of the disadvantaged. In Tierney's (1998) words, we "run the risk yet again of defining individuals in ways to who they are" (p. 55).

My dissertation research was with Chinese immigrant families, especially entrepreneurial families who because of their life circumstances spent more time making a living than tutoring or being with their children at home. I struggled with juxtaposing my own perspective of educational advancement as the top priority of a family life-values passed on from my own upbringing and derived from my own educational experiences $(\mathrm{Li}, 2000)$. Without constant reflection on my own subjectivity throughout the research process, I probably would not have recognized my own positionality, and would not have understood the sacrifices the families made in their immigrant experiences from their lived realities.

Tierney (1998) recommends that life history researchers undertake reflexive practice from a cultural perspective, through which they first clarify "what does culture mean, convey, or define for the researcher/author" (p. 55). Their search is not about why or how a person acts in a particular 
cultural way, but how to understand "the power of culture that defines those particular ways that enable people to act or not to act in specific ways" (p. 56). Tierney further argues that working from this perspective, the subjective $I$, then "shifts from him or her to us," which enables the researcher to come to terms with differences rather than see them as hurdles. Only from this positionality can an ESL life history researcher "talk intimately to and with power" (original italics, Marcus, 1998, p. 9).

(Re)identifying one's subjectivity reflexively in life history not only situates the researcher in the discourse of power but, more important, it benefits the often disadvantaged research participants in that they themselves are informed with critical thinking and are also able to talk to and with power. Kouritzin identifies two important benefits of life history for the participants: (a) they are provided opportunities of being listened to; and (b) it helps them "recognize moments of adversity in one's life and the uses to which they can be put" (p. 20). Beside these two points is another significant benefit that life history research can bring to ESL participants-personal transformation.

In my opinion, if life history is a form of inquiry for social change, as Kouritzin argues in her analysis of the benefits for theory and research (pp. 8-14), the benefits should not only be at the theory and research level, but more profoundly, at the grassroots level of the disadvantaged ESL participants. That is, the implications of life history research should potentially empower the participants to challenge the existing power structure that has shaped their life experiences, because "only power that springs from the weakness of the oppressed will be sufficiently strong to free both [the oppressor and the oppressed]" (Freire, 1970, p. 28). Criticizing the implicit conservatism of the interpretive model of social science research, Fay (1975) points out,

In a time of upheaval the interpretive model would lead people to seek to change the way they think what they or others are doing, rather than provide them with a theory by means of which they could change what they or others are doing, and in this way it supports the status quo. (original italics, p. 91)

One example comes from my own research with Chinese immigrant parents. Through the research one of the mothers realized the significance of learning English in her position as a female minority in Canadian society. She decided to give up her sewing factory job at the end of my research and take an opportunity provided by a provincial immigrant women's association to study English. She believes that by learning the English language she can change her status as a factory worker and secure a better job in the future. 


\section{Conclusion}

In this commentary I discuss an epistemological concern that Kouritzin has not addressed in her article: the issue of researcher's subjectivity, its potential pitfalls and benefits for ESL life history research, because life history as a form of narrative inquiry is "all about subjectivity" (Razack, 1993, p. 83). I argue that subjectivity influences how the researcher relates to the researched in the power relationship and how she or he interprets and represents the narrative truth and reality. An awareness of the inherent subjectivity will benefit both the researcher and the researched and empower both sides to work toward social change - at both theoretical and individual levels. Failing to recognize and identify one's subjectivity may result in enhancing rather than transforming the status quo.

\section{The Author}

Guofang Li is an SSHRC postdoctoral fellow in the Department of Language and Literacy Education at the University of British Columbia. Her research interests include family and community literacy, cross-cultural literacy and identity, second language education, and ethnographic research. She can be reached at guofang.li@ubc.ca.

\section{References}

Banks, J. (1993). The canon debate, knowledge construction and multicultural education. Educational Researcher, 22(5), 4-14.

Cary, L J. (1999). Unexpected stories: Life history and the limits of representation. Qualitative Inquiry, 5, 411-428.

Code, L. (1991). What can she know? Feminist theory and the construction of knowledge. Ithaca, NY: Cornell University Press.

Fay, B. (1975). Social theory and political practice. London: Allen \& Unwin.

Fine, M. (1994). Working the hyphens: Reinventing self and other in qualitative research. In N.K. Denzin \& Y.S. Lincoln (Eds.), Handbook of qualitative research (pp. 70-82). Thousand Oaks, CA: Sage.

Freire, P. (1970). Pedagogy of the oppressed. New York: Seabury Press.

Kouritzin, S.G. (2000). Bringing life to research: Life history research and ESL. TESL Canada Journal, 17(2), 1-35.

LeCompte, M.D. (1987). Bias in the biography: Bias and subjectivity in ethnographic research. Anthropology and Education Quarterly, 18, 43-52.

Li, G. (2000). Literacy outside school: Home practices of Chinese immigrant families in Canada. Unpublished doctoral dissertation, University of Saskatchewan.

Marcus, G.E. (1998). Ethnography through thick and thin. Princeton, NJ: Princeton University Press.

Peshkin, A. (1988). In search of subjectivity-One's own. Educational Researcher, 17(7), 17-21.

Razack, S. (1993). Storytelling as social change. In H. Barmerji (Ed.), Re/turning the gaze: Essays on racism, feminism and politics (pp. 83-100). Toronto, ON: Sister Vision.

Tierney, W.G. (1998). Life history' history: Subjects foretold. Qualitative Inquiry, 4, 49-61.

Wolcott, H.F. (1992). Posturing in qualitative research. In M.D. LeCompte, W.L. Millroy, \& J. Preissle (Eds.), The handbook of qualitative research in education (pp. 3-52). San Diego, CA: Sage. 